\title{
DRY MAGNETIC SEPARATION TECHNOLOGY FOR THE RECOVERY OF IRON MINERALS IN FINE-GRAINED STEEL SLAG
}

\author{
Changliang Shi ${ }^{1,2 *}$ Shengnan Wang ${ }^{1}$ - Gan Cheng ${ }^{1,2}$
}

${ }^{1}$ College of Chemistry and Chemical Engineering, Henan Polytechnic University, Jiaozuo, Henan, 454003, China; ${ }^{2}$ Henan Key Laboratory for Green and Efficient Mining \& Comprehensive Utilization of Mineral Resources, Henan Polytechnic University, Jiaozuo, Henan, 454003, China

\begin{tabular}{l} 
ARTICLE INFO \\
\hline Article history: \\
Received: 21. 03. 2017. \\
Received in revised form: 24. 08. 2017. \\
Accepted: 06. 09. 2017. \\
\hline Keywords: \\
Fine-grained steel slag \\
Dry magnetic separation \\
Self-developed magnetic separator \\
Magnetic system \\
Iron recovery \\
\hline DOI: http://doi.org/10.30765/er.40.1.02
\end{tabular}

\section{Introduction}

Steel slag is a type of solid waste emitted from the steel making process. It includes electric furnace slag, converter slag, and open-hearth furnace slag, with emissions account for around $15 \%$ to $20 \%$ of crude steel production. According to the World Steel Association (world steel), the world's crude steel production reached 1.6 billion tons in 2016; accordingly, it is estimated that at least 250 million

\begin{abstract}
:
Using the MagNet software package, a permanent magnetic circuit was simulated and a sectoriallyspliced magnetic system was designed. Consequently, a new roller permanent magnetic separator with different magnetic field intensities in each roller was developed. The modular structural design allows fine-grained minerals

with different magnetic susceptibility to be separated in one pass, according to their different processing characteristic. Steel slag, selected from a factory, was crushed, ground and sieved into different particle size ranges for the single-factor magnetic separation experiments. It was determined that the optimum value ranges for the particle size, magnetic separation distance and rotating frequency were $0.15 \mathrm{~mm}-0.3 \mathrm{~mm}, 10 \mathrm{~mm}$ $12 \mathrm{~mm}, 40 \mathrm{~Hz} \sim 60 \mathrm{~Hz}$, respectively; using the chosen parameter values of $0.2 \mathrm{~mm}, 11 \mathrm{~mm}$, and $40 \mathrm{~Hz}$, the concentrate recovery and concentrate grade of the new separation technology reached up to $52.78 \%$ and $64.74 \%$, in comparisson with the existing technology.

Thus, it was demonstrated that the self-developed separation technology has the potential to improve the iron recovery of the fine-grained steel slag.
\end{abstract}

tons of steel slag were produced, with a metallic iron content of up to 25 million tons [1]. In China alone, the crude steel production exceeded 804 million tons in 2016; taking into account a progressive increase of $0.8 \sim 0.9$ million tons per year, the resultant emission of steel slag is over 100 million tons. The excessive accumulation of steel slag not only causes serious environmental problems in the form of land, water and soil pollution, but also results in wastage of iron resources [2]. This last

\footnotetext{
* Corresponding author. Tel.13721456053

E-mail address: scl303@126.com
} 
problem is particularly pressing, as China still imports large quantities of iron ore.

It is expected that by 2018, China will account for $35 \%$ of the world's iron ore consumption. Iron is already one of the 10 kinds of mineral resources that China faces a shortage of. The recycling of steel slag not only protects the environment, but also promotes utilization ratio of resources. Hence, effective recycling of iron from steel slag, would not only alleviate environment pressures and improve economic efficiency, but would also reduce the industrial demand for iron ore in China [3-5].

Currently, the processing of steel slag from major plants in China is typically done by water quenching method. However, this method involves mineralaggregate problems and a difficult subsequent handling process due to high iron content [6]. In universities and research institutes, the technique used for efficient recycling of iron mainly include dry magnetic separation of bulk slag, wet stage grinding and magnetic separation, wet magnetic separation for full grain level, fine-grained level flotation, and gravity separation [7-9]. The wet separation and electromagnetic separation technologies suffer from high power and water consumption, whereas by contrast, dry permanent magnetic separation is a relatively simple, nodrying, energy-saving technology. However, the limitations of the existing magnetic equipment result in lower mineral separation accuracies for finegrained steel slag [10]. Development of technology for efficiently recycling iron resources from finegrained steel is, therefore, of utmost importance.

In the present study, a new roller permanent magnetic separator with four magnetic rollers was developed. The magnetic rollers have different magnetic field intensity. Four-sorting experimental studies for fine-grained steel slag, were performed to determine the best value of sorting parameters through single factor experiments. The desired magnetic concentrate recovery indices were achieved through high temperature modification experiments. Finally, a concentrated index was used to characterize the feasibility of the recycling steel slag iron with a new roller magnetic separator. In this paper, we present a self-developed new multiroller permanent magnetic separator, tailored to the physical characteristics of fine-grained steel slag. After separation, calculation of iron grade and recovery through titration experiment were performed so as to evaluate advantages and disadvantages of separator performance.

\section{Experimental material and its properties}

The selected steel slag was crushed to a particle size of $6 \mathrm{~mm}$, then ground to a particle size of $2 \mathrm{~mm}$, before being screened into particle size ranges for the magnetic separation experiments, as follows: $0.45 \mathrm{~mm}-2 \mathrm{~mm}, 0.3 \mathrm{~mm}-0.45 \mathrm{~mm}, 0.2 \mathrm{~mm}-0.3$ $\mathrm{mm}, 0.15 \mathrm{~mm}-0.2 \mathrm{~mm}, 0.1 \mathrm{~mm}-0.15 \mathrm{~mm}, 0.074$ $\mathrm{mm}-0.1 \mathrm{~mm}$. The process is illustrated in the flowchart shown in Fig. 1.

The results of multi-element chemical analysis of the steel slag are shown in Table 1. The iron distribution of different particle sizes is shown in Table 2.

As Table 1 shows, the grade of the selected steel slag was low, with $\mathrm{Fe} \%$ 21.84\%. The $\mathrm{SiO} 2$ and $\mathrm{CaO}$ content was higher, accounting for $15 \%$ and $43.69 \%$, respectively, that also were the associated minerals disseminated into iron. In order to obtain a magnetite concentrate with a high grade index, the minerals should be fully dissociated during magnetic separation. It can be seen in Table 2 that the fine-grained steel slag has higher iron content and the significance of recovery is obvious. The composition of the steel slag in terms of the main iron minerals' and its theoretical grade were determined using the X-ray analysis, as shown in Table 3.

Table 3 shows that the strongly magnetic minerals contained in the steel slag mainly include metallic iron, magnetite and ilmenite, with a total iron share of $80.82 \%$ and a relative mean theoretical grade of $69.7 \%$. This is the maximum theoretical value for the magnetic concentrate.

In principle, it is feasible to choose a weak-intensity magnetic separator to recover iron from steel slag. While, the hematite is weak magnetic mineral, and the iron share is $18.35 \%$. So, the magnetic intensity should not be too low. Although quartz and plagioclase have high iron contents, their iron grade and iron share are relatively low and cannot be recovered in a weak magnetic field.

In view of the factors such as fine particle size and magnetic properties, a new magnetic separator is adopted to separate the steel slag. Finally, the paper optimizes the sorting parameter and lays the technical foundation for the steel slag treatment. 


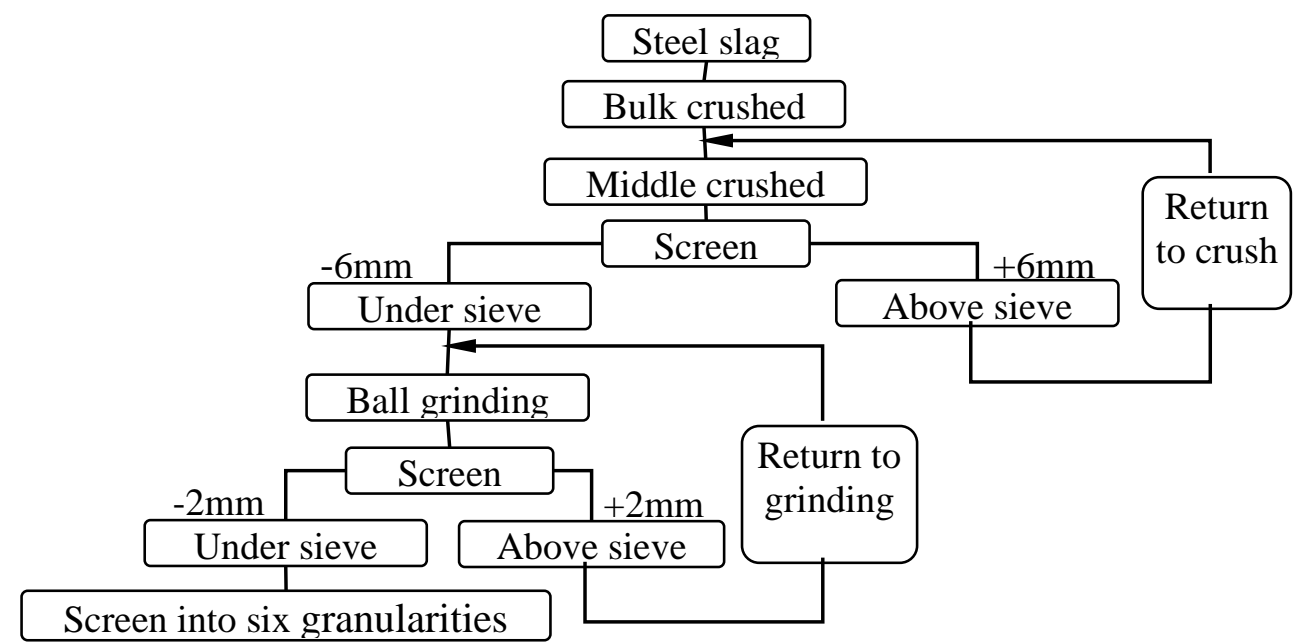

Figure 1. Flow chart for preparation of fine-grained steel slag

Table 1. Chemical composition of steel slag

\begin{tabular}{|c|c|c|c|c|c|c|c|c|c|c|}
\hline $\begin{array}{c}\text { Chemical } \\
\text { composition }\end{array}$ & $\mathrm{SiO}_{2}$ & $\mathrm{Fe}_{2} \mathrm{O}_{3}$ & $\mathrm{Al}_{2} \mathrm{O}_{3}$ & $\mathrm{CaO}$ & $\mathrm{MgO}$ & $\mathrm{MnO}$ & $\mathrm{P}_{2} \mathrm{O}_{5}$ & $\mathrm{FeO}$ & $\mathrm{S}$ & $\mathrm{TFe}$ \\
\hline Content/\% & 15 & 12.27 & 3.22 & 43.69 & 8.2 & 1.54 & 1.12 & 14.96 & 0.21 & 21.84 \\
\hline
\end{tabular}

Table 2 Iron distribution for different particle size of steel slag

\begin{tabular}{|c|c|c|c|c|}
\hline Particle size/mm & Yield $/ \%$ & Grade $/ \%$ & Fe\% /\% & Iron distribution /\% \\
\hline $0.45-2$ & 1.96 & 17.9 & 0.35 & 1.68 \\
\hline $0.3-0.45$ & 18.2 & 15.4 & 2.80 & 13.46 \\
\hline $0.2-0.3$ & 27.5 & 19.7 & 5.42 & 26.06 \\
\hline $0.15-0.2$ & 21.2 & 23.5 & 4.98 & 23.94 \\
\hline $0.1-0.15$ & 10.7 & 20.4 & 2.18 & 10.48 \\
\hline $0.074-0.1$ & 20.4 & 24.8 & 5.06 & 24.33 \\
\hline SUM & 100 & 20.8 & 20.8 & 100 \\
\hline
\end{tabular}

Table 3 Main iron mineral content and theoretical grade of steel slag.

\begin{tabular}{|c|c|c|c|c|c|c|c|}
\hline $\begin{array}{c}\text { Main iron } \\
\text { minerals }\end{array}$ & $\begin{array}{c}\text { Metallic } \\
\text { iron }\end{array}$ & Magnetite & Ilmenite & Hematite & Quartz & $\begin{array}{c}\text { Plagiocla } \\
\text { se }\end{array}$ & Total \\
\hline Content/\% & 7.09 & 10.06 & 11.29 & 6.01 & 29.55 & 36.00 & 100 \\
\hline $\begin{array}{c}\text { theoretical } \\
\text { grade /\% }\end{array}$ & 100 & 72.40 & 36.80 & 70.00 & 0.64 & 0.39 & 24.78 \\
\hline Iron share /\% & 30.93 & 31.77 & 18.12 & 18.35 & 0.82 & 0.61 & 100 \\
\hline
\end{tabular}

3 Self-developed multi-roller permanent magnetic separator

\subsection{Magnetic system design}

The key consideration when designing a magnetic separator is the performance of its magnetic system, as this directly affects the whole separation process. In this study, eight fan-shaped permanent magnets, with the $\mathrm{N}$ and $\mathrm{S}$ poles arranged alternately, were circumferentially distributed along the roller using the splicing technique, and the eight magnetic yokes were entrained in the middle of adjacent magnets to form a closed loop magnetic system structure. 
Following this, the multi-set structures were radically arranged along the roller using extrusion technology, to form the magnetic roller. A simplified physical model of the magnetic system is shown in Fig. 2.

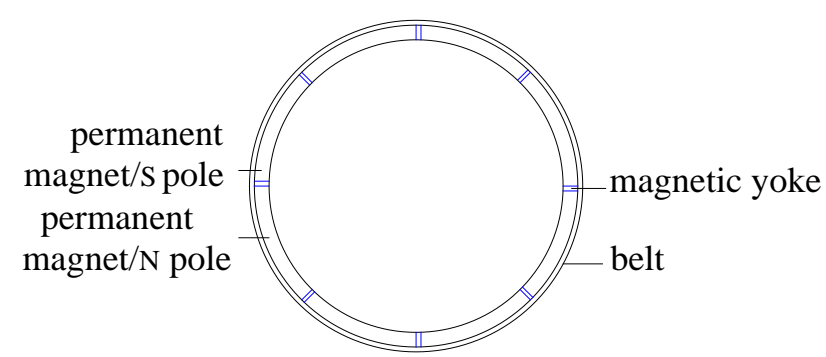

Figure 2. A simplified physical model of the magnetic system

MagNet electromagnetic field analysis software is a low frequency electromagnetic analysis software,it is used to solve the problem of the magnetic field in aerospace, automobile, electric power, magnetic separation equipment, medical equipment, electronic products and other industries. The simulation results for the magnetic system, simulated using software package MagNet [11], are shown in Fig. 3.

Fig. 3 (a) shows that the magnetic force lines could effectively be gathered due to the magnetic yoke configuration, and the magnetic field intensity along the circumference of magnetic roller are relatively gentle, with a variation amplitude of $0.2 \mathrm{~T}$. Also, it is evident that there was less magnetic flux leakage along the splicing line. All of these features are useful, for they enable the fine-grained steel slag to repeatedly flip during the sorting process so as to reduce the inclusions in the tailings and thereby improve the magnetic concentrate grade.

Fig. 3 (b) shows that the values of the magnetic field intensity are higher than $0.15 \mathrm{~T}$, up to a maximum of $0.5 \mathrm{~T}$, corresponding to a vertical distance of 0 $50 \mathrm{~mm}$ from the surface of the magnetic roller. When the vertical distance is between $50 \mathrm{~mm}$ $150 \mathrm{~mm}$, the magnetic field values are between 0.04 $\mathrm{T}-0.15 \mathrm{~T}$. When the vertical distance is between $150 \mathrm{~mm}-350 \mathrm{~mm}$, the values are between $0-0.04 \mathrm{~T}$. When the vertical distance is over than $350 \mathrm{~mm}$, the value of magnetic field intensity is 0 . The results indicate that the magnetic system design has the characteristics of higher echelon change value of magnetic field intensity, large magnetic field separation space and deep magnetic separation distance. All of these are conducive to efficient enrichment of iron in fine-grained steel slag.

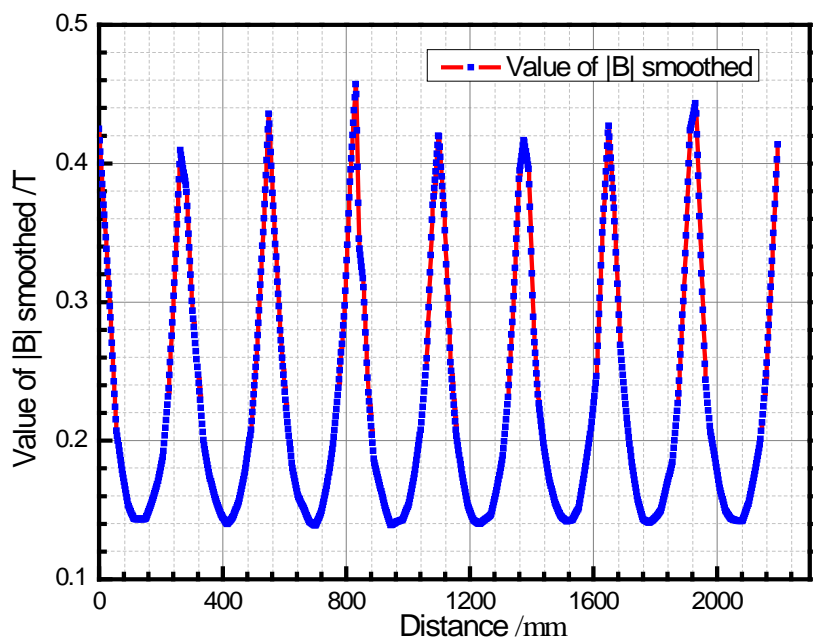

(a)Magnetic field intensity along the circumference of magnetic roller

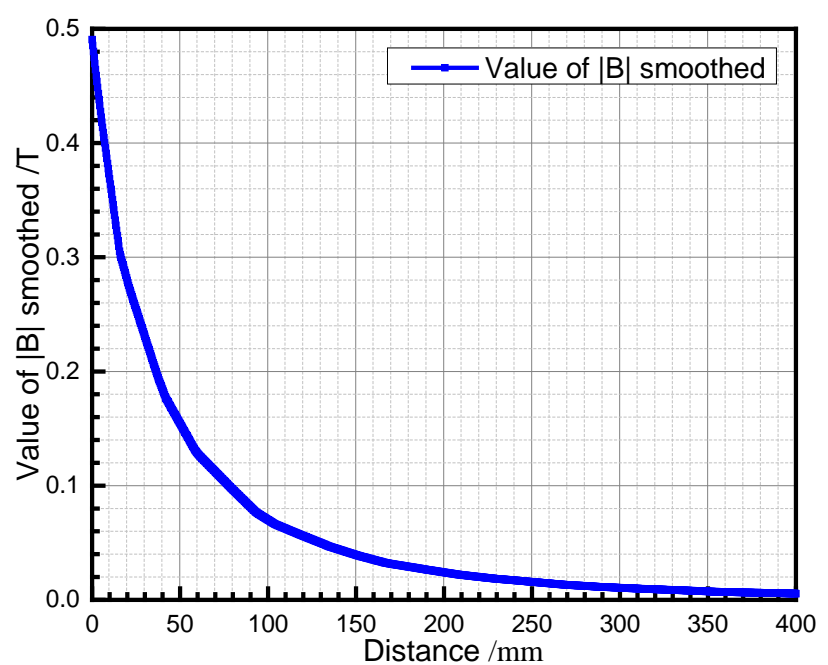

(b) Magnetic field intensity along the vertical distance of magnetic roller

Figure 3. Simulation results for the magnetic system of the new roller magnetic separator

\subsection{The structure and sorting characteristic of magnetic separator}

A reasonable mechanical design can improve technical performance of a magnetic separator to some extent, thereby realizing the maximum revenue possible for mineral separation [12]. The structure and sorting characteristic of the new roller magnetic separator are shown in Fig. 4. 


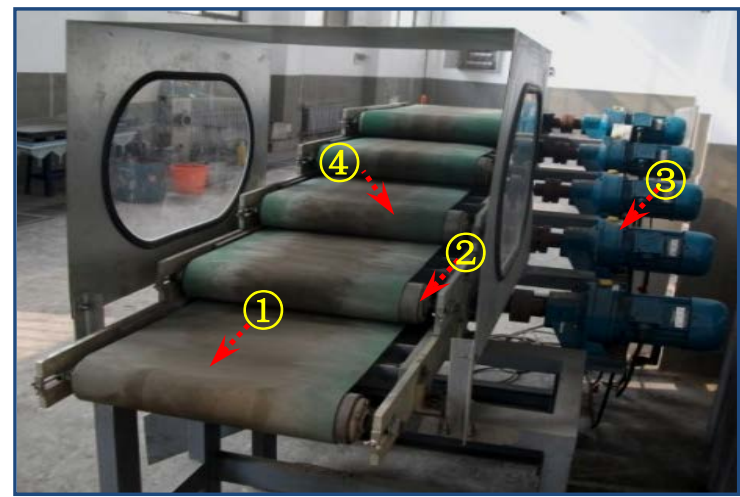

(1):belt; (2):magnetic roller I; (3):variable frequency motor; (4):magnetic roller II)

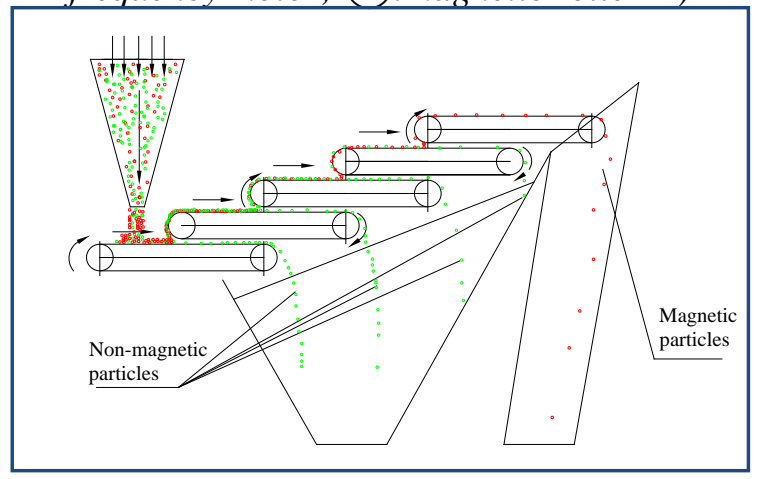

Figure 4. Structure and sorting characteristic of the new roller permanent magnetic separator

As can be seen in Fig. 4, the multi-level magnetic roller setting and modular structure design allow the separator to be adjusted according to the characteristics of the minerals being processed so as to achieve different sorting effects. Furthermore, by using multi-level and multiple sorting methods, combined with a circumferential magnetic field distribution, it is possible to significantly reduce inclusions of minerals in fine-grained steel slag. Moreover, the steel slag used in the experiment have complex magnetic mineral compositions and quite different magnetic properties. Therefore, adjusting the system according to the sorting characteristics can greatly simplify the separation process and improve the efficiency of minerals separation. Each of the different magnetic rollers has different magnetic field intensity; therefore, the four times separation process can not only achieve efficient separation of different compositions of iron magnetic minerals, but it can also greatly enhance the iron concentrate grade [13].

Compared with the conventional magnetic separator [14], the new roller permanent magnetic separator has the following advantages:1) it can achieve the separation of different magnetic compositions of steel slag; 2) using the same background magnetic field, it can not only achieve the separation of useless mineral tailings in steel slag, but can also effectively remove the non-magnetic materials from the magnetic materials. In this way, the enrichment of useful minerals is enhanced, and the magnetic concentrate grade is improved, both through the alternating changed direction of magnetic field and by sorting with the multi-level magnetic roller.

In this study, we explored the influence of separation parameters on the magnetite concentrate grade and recovery by conducting the single factor experiments. The chosen factors included particle size, magnetic separation distance, and rotating frequency. In addition, the experiments helped definite the optimum separation parameters and improved the efficiency of the recovery process.

\section{Results and Discussion}

\subsection{Experimental research of particle size influence to the concentrate index}

Figure 5 shows the dissociation of mineral compositions in steel slag at different particle sizes, imaged using a stereo microscope. With a decrease in the particle size, the dissociation of mineral composition is apparent. At a particle size of $0.074 \mathrm{~mm}-0.15 \mathrm{~mm}$, the minerals become agglomerated. The iron distribution for the different particle sizes is shown in Table 2, which indicates that the suitable particle size is confined to the middle classifier of $0.15 \mathrm{~mm}-0.3 \mathrm{~mm}$. It can also be inferred from the images that most of the monomer dissociation and disseminated combined iron and iron oxide in the steel slag are grey-black, with some brightly-colored areas corresponding mainly to silicates and other non-magnetic minerals.

In order to further optimize the particle size, the particle size influence on the magnetite concentrate index was investigated. The experimental results for the relationship between the variables is shown plotted in Fig. 6.

Fig. 6 shows that the magnetic concentrate grade was higher than the feed grade, with a greatly improved amplitude value of about $30 \%$; thus demonstrating that the new roller magnetic separator has excellent sorting properties. Fig. 6 illustrates that the value of concentrate grade gradually improved with a decreasing particle size, while under the same conditions the value of concentrate recovery dropped sharply. The reason for this is that 
iron minerals and gangue contained in the bulk intergrowth minerals cannot be fully dissociated; instead, they may be recovered as a magnetic concentrate. Fig. 6 also shows that the concentrate recovery rebounds at a particle size of $0.074 \mathrm{~mm}-$ $0.1 \mathrm{~mm}$ particle size, due to the phenomena of mineral agglomeration. Here, we chose $0.15 \mathrm{~mm}-$ $0.3 \mathrm{~mm}$ as the suitable particle size range for steel slag (as it represents a tradeoff between the values of concentrate recovery and concentrate grade),and we therefore present a comprehensive analysis of this size range.

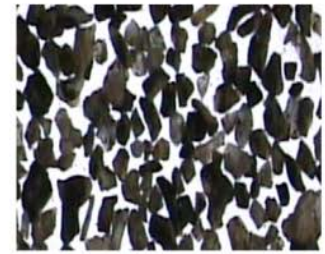

$0.3 \mathrm{~mm}-0.45 \mathrm{~mm}$

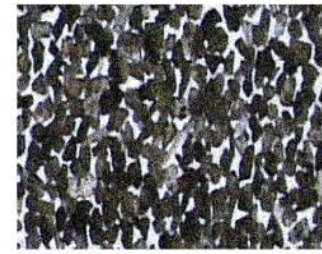

$0.2 \mathrm{~mm}-0.3 \mathrm{~mm}$

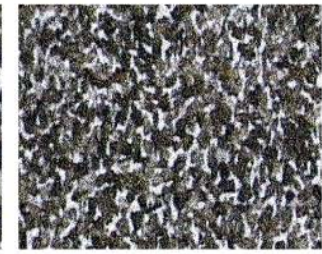

$0.15 \mathrm{~mm}-0.2 \mathrm{~mm}$

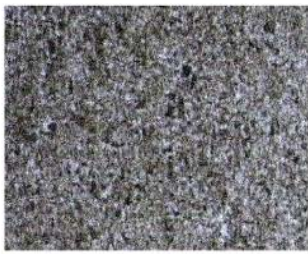

$0.1 \mathrm{~mm}-0.15 \mathrm{~mm}$

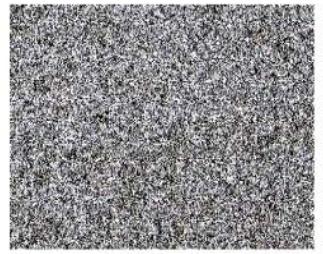

$0.074 \mathrm{~mm}-0.1 \mathrm{~mm}$

Figure 5. The dissociation of mineral compositions in steel slag at different particle size

\subsection{Experimental research of magnetic separation distance influence to the concentrate index}

Taking the average value of the optimal particle size as $0.2 \mathrm{~mm}$, the relationship between the magnetic separation distance and the concentrate index was investigated. This relationship is shown plotted in Fig. 7.

Fig. 7 shows that the value of concentrate grade increases gradually with an increase in the magnetic separation distance, and that the overall distribution of values is higher than the feed grade of $21.40 \%$.

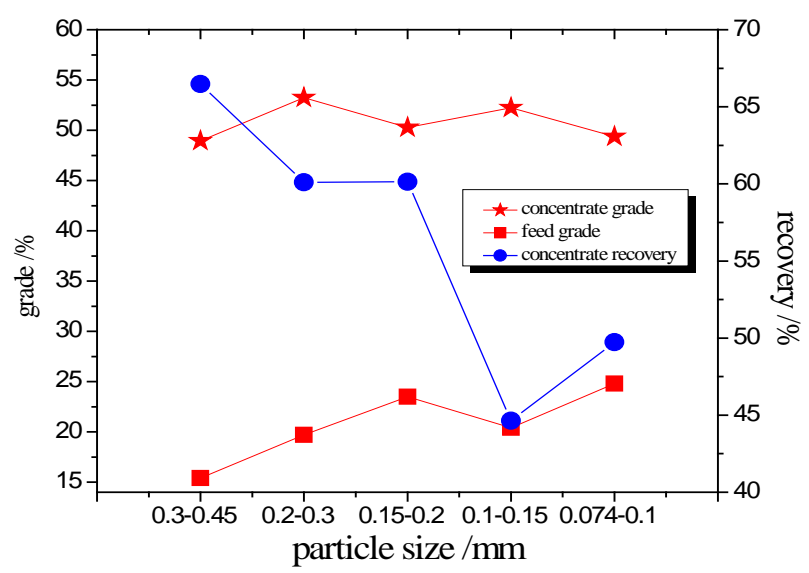

Figure 6. Relationship between concentrate index and particle size

From the data shown in Fig. 3, we know that the magnetic intensity, $\mathrm{Hy}$, decreases exponentially with vertical distance $y$. Thus, an increase in the magnetic separation distance causes y to increase; hence, the magnetic field intensity sharply decreases, along with the magnetization intensity of the magnetic minerals in the steel slag. This lowers the magnetic inclusion phenomenon and enhances the magnetite concentrate.

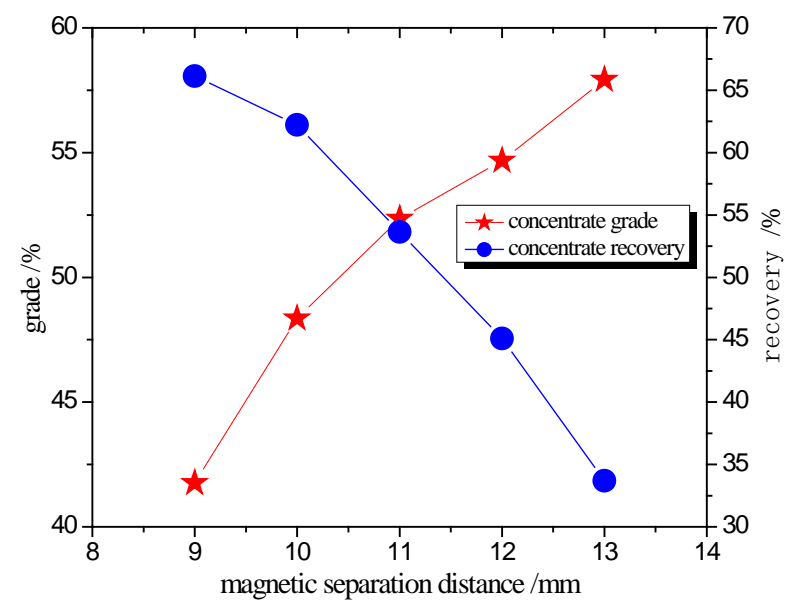

Figure 7. Relationship between concentrate index and magnetic separation distance

Nevertheless, for some weakly-susceptible magnetic minerals, the lowered magnetic force cannot meet the threshold value, causing the value of concentrate recovery to drop. When the magnetic separation distance is between $10 \mathrm{~mm}-12 \mathrm{~mm}$, the concentrate grade and concentrate recovery are higher, with values of $52.35 \%$ and $53.64 \%$ respectively, at a separation distance of $11 \mathrm{~mm}$. 


\subsection{Experimental research of rotating frequency influence to the concentrate index}

In the present study, the relationship between the rotating frequency and the concentrate index was also investigated, at a particle size of $0.2 \mathrm{~mm}$. This relationship is shown plotted in Fig. 8.

Fig. 8 shows that with an increase in the rotating frequency, the concentrate recovery shows a minimum value at $60 \mathrm{~Hz}$. The value of concentrate grade, on the other hand, shows a maximum at 40 $\mathrm{Hz}$; thereafter, it decreases, but with a smaller change in amplitude compared to the recovery.

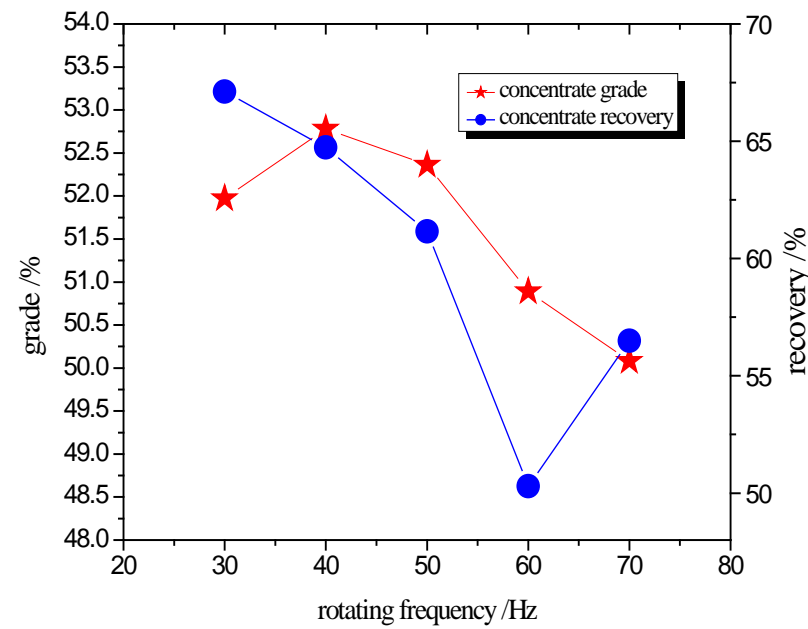

Figure 8. Relationship between concentrate index and rotating frequency

These observations can be attributed to the following reasons: the total iron composition of the strongly-susceptible magnetic minerals in steel slag is $80.82 \%$, whereas the overall content of weaklysusceptible minerals, which have low iron content, is much higher. Therefore, the strongly-susceptible minerals will be magnetized instantly, and will form magnetic chains, which can produce a secondary magnetic field and display magnetic field superposition. Hence, the weakly-susceptible magnetic minerals will be magnetized by the new external magnetic field and will then be mixed up with or will attach to the surface of the magnetic chains.

As the rotation frequency is gradually increased, the residence time for magnetic chains becomes short; and the secondary magnetized time for weakly magnetic susceptibility minerals decreases. Also, the impact force of the surrounding particles increases and becomes higher than the binding force, causing them to be separated again. The non- magnetized and separated weakly-susceptible magnetic minerals will be lost to the tailings, and the magnetite concentrate recovery may therefore be reduced. However, for higher values of rotation frequency, the surrounding particles have a very short contact time with the magnetic chains. The separation of weakly magnetic minerals will be effectively adsorpted and enriched, therefore causing the value of concentrate recovery to increases lightly.

It should also be noted that there is inevitably some mixing of non-magnetic minerals in magnetic chains. As the rotating frequency increases and the residence time shorten, the tumbling time is not sufficient for concentrate recovery. This results in the mixed or attached minerals not being discharged in time, thereby lowering the concentrate grade. On the other hand, the loss of weakly-susceptible minerals can also lower the concentrate grade; however, their iron content tends to be very low, and thus the resultant amplitude reduction is not large.

The data presented in Fig. 8 also shows that as the rotation frequency increases, the mineral loss rate is higher. The analysis indicates that in the rotating frequency range of $40 \mathrm{~Hz}-60 \mathrm{~Hz}$, there is a tradeoff, whereby the optimal concentrate recovery and concentrate grade values are reached; for example, at $40 \mathrm{~Hz}$, these values were $64.74 \%$ and $52.78 \%$, respectively.

The single factor experiments, conducted using the optimum the particle size range of $0.15 \mathrm{~mm}-0.3$ $\mathrm{mm}$, have thus enabled determination of the optimum magnetic separation distance and the rotating frequency ranges, which are $10 \mathrm{~mm}-12 \mathrm{~mm}$ and $40 \mathrm{~Hz}-60 \mathrm{~Hz}$, respectively.

\subsection{Comparative experiments}

A set of experiments were also carried out to compare the recovery performance of a conventional roll magnetic separator and the selfdeveloped magnetic separator in the separation of iron minerals in fine-grained steel slag. The experiments with the roll separator used a particle size of $0.2 \mathrm{~mm}$ and different rotating frequencies, whereas the experiments with the self-developed separator used the same particle size with a magnetic separation distance $11 \mathrm{~mm}$, which corresponds to the former rotating frequency. The experimental results for both systems are compared in Fig. 9. 


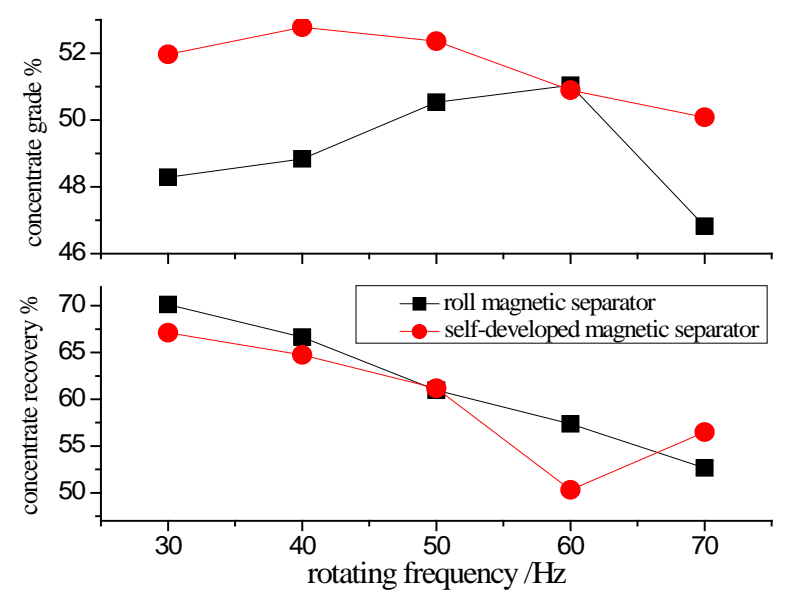

Figure 9. Comparative experimental results at different rotating frequency

Figure 9 shows that the value of concentrate grade obtained using the self-developed separator is higher than that obtained using the roll separator, at all the different rotating frequency used, except for $60 \mathrm{~Hz}$ where the performance of both separators is identical. Furthermore, the values of concentrate recovery for the two separation technologies are similar. Thus, we conclude that the new (selfdeveloped) separation technology is more suitable for fine-grained steel slag, with the concentrate recovery and concentrate grade reaching 52.78\% and $64.74 \%$, respectively, using the optimized sorting parameters. The new separation technology clearly demonstrates a strong effect on the separation of magnetic minerals and the recovery of iron in waste slag.

\subsection{Experimental results for the modified steel slag}

Through the experiments in which the magnetic behavior of fine-grained steel slag was tested at different particle sizes, we observed that the suitable particle size range was $0.15 \mathrm{~mm}-0.3 \mathrm{~mm}$. The average magnetic concentrate recovery was $52.16 \%$, the maximum magnetic concentrate recovery was $66.13 \%$ (which is a low value), and that the magnetic concentrate grade increased by $20-30 \%$. Therefore, it is evident that the yield and the recovery of the magnetic concentrate needs to be improved. There is a certain proportion of weakly magnetic minerals in steel slag. Therefore, magnetic concentrate recovery will probably not be high, as these materials do not possess sufficient magnetism for the new magnetic separator to be effective. In order to verify this, we analyzed the magnetite content of the suitable particle size using a magnetic tube, which enabled calculation of the magnetite iron content.

This section describes how the desired magnetic concentrate recovery index was achieved through high temperature and high voltage modification experiments. ADC voltage device was used to shock the fine steel slag. After 10 minutes, $500 \mathrm{~g}$ of slag were sampled to analyze the magnetite iron content. The slag was then roasted, and after 60 minutes, another $500 \mathrm{~g}$ were sampled for analysis. Table 4 shows the magnetite iron recovery before and after modification.

Table 4 Magnetite iron recovery with magnetic tube determination prior and after modification

\begin{tabular}{|c|c|c|c|c|c|c|}
\hline \multirow{2}{*}{$\begin{array}{c}\text { Particle } \\
\text { size/mm }\end{array}$} & \multicolumn{2}{|c|}{ High voltage modification } & \multicolumn{2}{c|}{$\begin{array}{c}\text { High temperature } \\
\text { modification }\end{array}$} & \multicolumn{2}{c|}{ The difference value /g } \\
\cline { 2 - 5 } & $\mathrm{BM}$ & $\mathrm{AM}$ & $\mathrm{BM}$ & $\mathrm{AM}$ & $\begin{array}{c}\text { High voltage } \\
\text { modification }\end{array}$ & $\begin{array}{c}\text { High } \\
\text { temperature } \\
\text { modification }\end{array}$ \\
\hline-0.3 & 107.70 & 92.21 & 107.70 & 131.56 & -15.49 & 23.86 \\
\hline+0.1 & 100.60 & 89.24 & 100.60 & 122.85 & -11.36 & 22.25 \\
\hline $0.15-0.3$ & 119.05 & 101.99 & 119.05 & 145.44 & -17.06 & 26.39 \\
\hline
\end{tabular}

"BM”stands for "Before Modification”; “AM”stands for “After Modification”

As Table 4 shows, the magnetite iron recovery of steel slag dropped by $13 \%$ on average and the fluctuation was large after the high-voltage modification. However, after the high temperature modification, the recovery increased by $22 \%$ on average, with a smaller fluctuation. The reasons for this are likely as follows: the specific susceptibility of moderately strong magnetic minerals will 
decrease under high voltage, resulting in a decrease in the probability of adsorption of moderately strong magnetic minerals; on the other hand, hightemperature roasting can make some weakly magnetic minerals strongly magnetic, resulting in an increase in the magnetite iron content.

Using lignite as a reducing agent, the oxidationreduction reaction of the best grade $0.15-0.3 \mathrm{~mm}$ steel slag was carried out in a high-temperature roaster. The C-content ratio is the ratio of carbon content in coal and the quality of steel slag in mineral. The resulting data are shown plotted in Fig. 10, and it was assumed that the grade of the raw ore was $25 \%$.

As shown in Fig. 10, when the C-content ratio is $6: 1$, the concentrate recovery of the modified steel slag will drop 2.63 percentage points at $850^{\circ} \mathrm{C}$; when the C-content ratio is $10: 1$, the concentrate recovery of the modified steel slag will increase 0.28 percentage points at $850^{\circ} \mathrm{C}$; when the $\mathrm{C}$-content ratio is $8: 1$ and the temperature is $1150^{\circ} \mathrm{C}$, the magnetic concentrate recovery of the modified steel slag is $91.78 \%$, which increases 24.66 percentage points and the effect is very obvious.

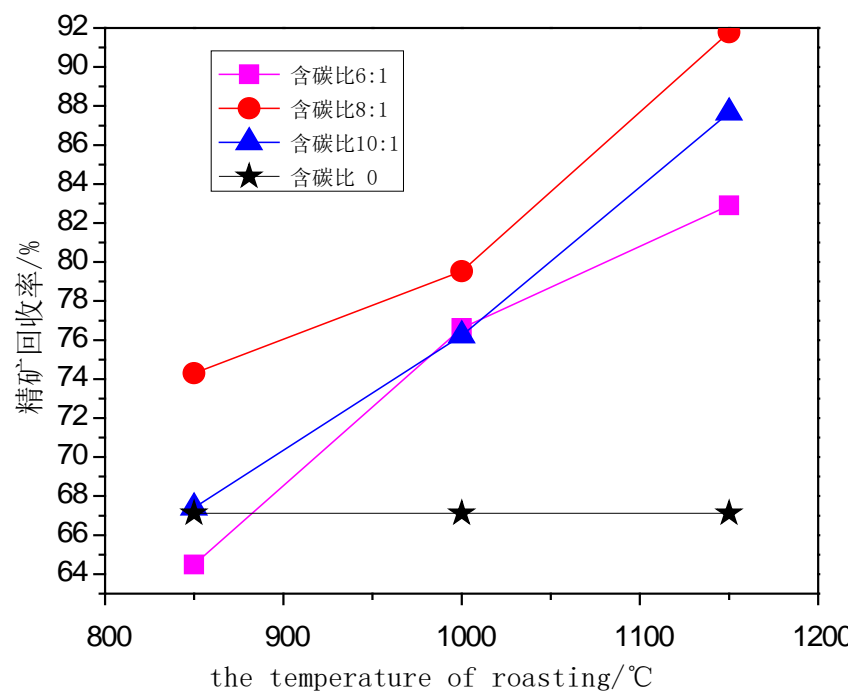

Figure 10. Dry magnetic behavior contrast of steel slag for different high-temperature roasting

As shown in Fig. 10, for a C-content ratio of 6:1, the concentrate recovery of the modified steel slag dropped by $2.63 \%$ at $850{ }^{\circ} \mathrm{C}$, whereas for a Ccontent ratio of $10: 1$, the concentrate recovery increased by $0.28 \%$ at the same temperature. On the other hand, when the $\mathrm{C}$-content ratio and the temperature were $8: 1$ and $1150^{\circ} \mathrm{C}$ respectively, the magnetic concentrate recovery of the modified steel slag was $91.78 \%$, which is an increase of $24.66 \%$, clearly illustrating the temperature effect.

As it is widely known, steel slag is formed from liquid poured from a smelting furnace [15]. When the furnace liquid is poured, its temperature is about $1200^{\circ} \mathrm{C}$, high enough to meet the requirements of roasting. By adding lignite to the cooling pool and controlling particle size, this technology may be used in industry to improve the moderately-strong magnetic mineral content, as well as the separation efficiency of iron minerals.

\section{Conclusions}

In the present study, a new magnetic separator was designed and magnetic separation experiments were carried out to optimize the main sorting parameters according to the characteristics of the selected steel slag. An efficient recovery of iron in the finegrained steel slag was obtained. The main conclusions are:

(1) With designing the closed-loop permanent magnetic system by splicing and extrusion of eight fan-shaped permanent magnets, it was possible to realize the echelon changes of magnetic field intensity with higher values. The magnetic system thus produced displays characteristics such as more circumferential alternating times, minimal magnetic flux leakage, large magnetic separation space, and deep magnetic separation distance, thus efficiently contributing to iron enrichment in the fine-grained steel slag.

(2) The self-developed magnetic separator has a multi-roller setting and a modular structural design, enabling it to be adjusted to achieve different sorting effects depending on the characteristics of the minerals being processed. At the same time, these characteristics, combined with the circumferential distribution of magnetic field, enhance the probability of reducing mineral inclusions.

(3)A process was designed for the preparation of fine-grained steel slag, and four-sorting experiments were carried out on the recovery of steel slag iron. The single factor experiments enabled determination of the optimum value ranges of the particle size (0.15 mm-0.3 mm), magnetic separation distance (10 mm-12 mm), and rotating frequency (40 Hz-60 $\mathrm{Hz}$ ). Correspondingly, a comparative experimental was carried out using parameter values of $0.2 \mathrm{~mm}$, $11 \mathrm{~mm}$, and $40 \mathrm{~Hz}$, respectively. It was found that the concentrate recovery and concentrate grade reached $52.78 \%$ and $64.74 \%$, respectively. Thus, the 
new separation technology has a beneficial effect on iron recovery from waste slag.

(4) The magnetite iron recovery of steel slag was found to drop after high voltage modification and increase after high temperature modification. Furthermore, for a C-content ratio of8:1 at a temperature of $150^{\circ} \mathrm{C}$, the magnetic concentrate recovery of the modified steel slag was $91.78 \%$.

\section{Acknowledgements}

This research was financially supported by the Fundamental Research Funds for the Universities of Henan Province (NSFRF140108), the Key Laboratory Fund Project of Henan Province (Grant No.S201615, and the Key Project of Science and Technology Innovation of the Education Department, Henan Province (Grant No.14A440014).

\section{References}

[1] Zhu, X.B.,2017. Global crude steel production increased by $0.8 \%$ in 2016, China Metallurgical news, 02-10 (001).

[2] Li, Y.J., The analysis of the concentration index of crude steel in China's steel industry in 2016, China Steel Focus 2017, 04 (2017) 4-9.

[3] Zhang, H.W., Hong X., An overview for the utilization of wastes from stainless steel industries, Resources, Conservation and Recycling, 55 (2011), 3, 745-754.

[4] Jiang, Y.X.: Treatment and complex utilization of steelmaking slag at Masteel New Area, Iron \& Steel, 46 (2011), 5, 89-92.

[5] Pu, H.Y., Zhang, Y.H.: On the comprehensive utilization of mineral resources in our country, Multipurpose Utilization of Mineral Resources, 32 (2001), 4, 19-22.

[6] Wei, Y., Lu, D., Li, Z.F.: Research on comprehensive utilization of steel slag by magnetic separation, Mining and Metallurgical Engineering, 2 (2009), 1, 48-49.

[7] Li, Y.F., Yao, Y., Wang, L.: Recycling of industrial waste and performance of steel slag green concrete, Journal of Central South University, 5 (2009), 768-773.

[8] Das, B., Prakasha, S., Reddya, P.S.R., Misraa, V.N.: An overview of utilization of slag and sludge from steel industries, Resources, Conservation and Recycling, 50 (2007), 1, 4057.
[9] Menad, N., Kanari, N., Save, M.: Recovery of high grade iron compounds from LD slag by enhanced magnetic separation techniques, International Journal of Mineral Processing, 126 (2014), 1-9.

[10] Khvatov, U.A., Armashova, Z.P, Maly, V.M., Gardash, N.K., Kolos, V.P., Knyazhitsky, Y.A., Kaptilaya, L.V., Sheludko, V.P.: Utilization of the tailings from wet magnetic separation at the Krivoy Rog Gok, Magnetic and Electrical Separation. 6 (1995), 3, 179-184.

[11] Liu, P.: Study on Fine Coal Strong Permanent Magnet Magnetic Filter [D]. Henan Polytechnic University, 2010.

[12] Luo, L.Q., Huang, H., Yu, Y.F.: Characterization and technology of fast reducing roasting for fine iron materials, Journal of Central South University, 8, 2012. 2272-2278.

[13] Shi, C.L., Zhang, Y.S., Jiao, H.G.: Development and analysis of permanent roll and drum magnetic separator, Mining Engineering, 8 (2010), 4, 35-38.

[14] Shi, C.L., Zhang, Y.S., Jiao, H.G.: Module roller permanent magnetic separator: China, ZL 200910066227.5, 2012.

[15] Chen, F., Yao, Q.,Tian, J.Y.: Review of ecological restoration technology for mine tailings in China, Engineering Review, 36 (2016), 2, 115-121. 